\title{
Aljamas y concejos en el Reino de Castilla durante la Edad Media
}

\author{
Francisco Ruiz Gómez *
}

Las comunidades judías del reino de Castilla durante la Edad Media gozaron de una entidad propia, cuya manifestación más importante, en lo referido a la autonomía organizativa, fue la aljama. Nos parece evidente que hubo una relación entre el desarrollo histórico de las ciudades y villas de la España Cristiana, y el de las juderías existentes en una parte importante de ellas. Recientemente, hemos podido comprobar, cómo la evolución del poblamiento rural castellano en general, se reflejó, de forma directa, en la aparición de las juderías '. De hecho, los fueros de la repoblación de los siglos XI y XII contienen las primeras disposiciones sobre el régimen de gobierno de las juderías y una aproximación a la definición de su estatuto religioso. El proceso culminó a finales del siglo xil y principios del siglo XIII, con la aparición de las aljamas como institución jurídico-administrativa para el gobierno de las comunidades judías.

Las instituciones de la aljama se correspondían con la organización religiosa propia del judaísmo, por lo que muchos de sus dirigentes fueron también rabinos ilustres y respetados. Sin embargo, la comunidad era, al mismo tiempo, una realidad política y social y por este motivo, la configuración de sus órganos de gobierno, y las decisiones tomadas por los mismos, tienen que ser contemplados dentro de los procesos históricos en los que se desenvolvieron. A este respecto, resulta obvio que el marco de desarrollo de las aljamas fueron los concejos, y que el régimen político de éstos influyó de forma decisiva sobre aquéllas.

Esta idea, que constituye una revisión no confesional de planteamientos historiográficos tradicionales, fue expuesta por BAER a partir del es-

* Universidad de Castilla-La Mancha.

Nos referimos a nuestra ponencia, presentada en el Congreso Internacional sobre Judíos y Conversos en la Historia, celebrado en Ribadavia en octubre de 1991, cuyo título fue «Juderías y aljamas en el mundo rural castellano durante la Edad Media", inédita por el momento. 
tudio del régimen de las aljamas del reino de Aragón y Cataluña principalmente ${ }^{2}$. En el presente trabajo, vamos a desarrollar esta tesis en relación con las juderías castellanas desde el siglo XIII hasta la primera mitad del $x v$.

\section{EL RÉGIMEN DE GOBIERNO DE LAS ALJAMAS}

La aljama es la organización comunitaria existente en una judería, cuya finalidad principal es la creación de un régimen de gobierno propio y el mantenimiento de la sinagoga y demás servicios religiosos. Según la tradición, el gobierno autónomo de cada comunidad judía estaba inspirado en las atribuciones del primitivo Sanhedrim. Perdida su independencia en la época del cautiverio de Babilonia, cada comunidad recogió su legado; aunque con grandes limitaciones, entre otras, la imposibilidad de crear la Ley Judía. De forma que, en adelante, sólo se permitió su aplicación e interpretación. Esta Ley, la Torah, y su complemento, el Talmud, fue la base sobre la que descansaba el régimen político de las aljamas. Sin embargo, la Ley no definía una forma de gobierno específica, por lo que cada aljama tuvo libertad para organizarse de la forma que resultase más conveniente, siempre que el sistema adoptado fuera conforme con los principios religiosos y superara el dictamen de los doctores de la Ley. Este margen de autonomía política permitió que el régimen de gobierno evolucionase más fácilmente, independizándose de los principios religiosos inamovibles en los que se basaba, y adaptándose a las circuntancias históricas en las que cada comunidad se desenvolvía ${ }^{3}$. Y es aquí, cuando se aprecia la relación existente entre los concejos y las aljamas, como conjuntos institucionales complementarios, para la articulación de dos comunidades religiosas diferenciadas, pertenecientes a una misma estructuración social.

En el Judaísmo, las ceremonias de culto público y la oración en común exigen la presencia de un mínimo de diez varones. Este número (Minyan)

2. Baen, Y., Historia de los judíos de la España Cristiana, 2 vols., passim. Madrid 1981.

3 El régimen de las aljamas no ha sido objeto de estudio detenido por los especialistas. BAER, en su Historia de los judíos... y Ríos, Amador de los, en su Historia de los judios de España y Portugal, 3 vols. reed. Madrid 1974, se refieren a esta cuestión en distintos capítulos. La obra que lo trata de forma más específica es la de NEUMAN, A., The Jews in Spain. Their social, political and cultural life during the Middle Ages, II vols. Philadelphia 1944. Sin embargo, el trabajo de Neuman describe la organización de las aljamas como una realidad permanente, sin atender a las circunstancias históricas que determinaron su aparición y evolución posterior. No obstante, es de gran utilidad como fuente de información para este apartadio de nuestro trabajo. 
puede ser considerado como referencia válida para la constitución de una comunidad judía y, potencialmente, de una Aljama. Una vez constituida la comunidad, cada uno de los individuos que la integran conserva todos sus derechos, entre otros el de separarse de ésta cuando no acepta sus normas. Si bien, la comunidad dispone de recursos legales para aplicar castigos a los disidentes y decretar la expulsión (herem) en los casos graves de violación de las normas comunes ${ }^{4}$. Además de estas parcelas de autonomía individual, en las aljamas se desarrolla una dinámica interna de grupos profesionales, religiosos y vecinales, en forma de gremios y cofradías que se dotan de estatutos internos específicos e incluso poseen sinagogas propias ${ }^{5}$. Por lo tanto, podemos afirmar que, aunque las creencias religiosas constituyen un elemento de integración e institucionalización de la comunidad judía, la forma de articularse en la práctica, esto es, en su significado social y político, no presenta diferencias sustanciales con respecto a la forma de organizarse la población cristiana de su entorno.

Podemos suponer que, en principio, durante la época de la repoblación, las juderías, y sobre todo las de las zonas rurales, se agrupaban, más o menos espontáneamente, en torno a las sinagogas y sus rabinos, a veces, simplemente, el vecino más piadoso y versado en la Torah. Y así, de forma común, junto a las ceremonias religiosas, tomaban acuerdos que obligaban al conjunto de sus miembros. A partir de los siglos XII y XIII, en el seno de la comunidad había surgido una minoría dirigente que disponía del poder político y económico y forzaba la transformación de las estructuras comunales anteriores. Al igual que con respecto al régimen de los concejos se habla de la existencia de un señorío colectivo; en el caso de las aljamas, hay que considerar que sus ordenanzas (takkanot), que empiezan a redactarse por esta época, reflejan el acceso de este grupo a las instancias del poder vecinal. Sin olvidar, por otra parte, sus relaciones con la corona o los otros grandes señoríos existentes en cada caso.

4 Los derechos individuales y colectivos en la aljama, y sus fundamentos religiosos, fueron analizados con detalle por ALBECK, Sh., "The principles of government in the jewish communities of Spain until the 13th century», en Zion, XXV (1960), n. ${ }^{\circ} 2$, págs. 85-121.

5 Las más conocidas son las cofradías de las aljamas aragonesas. Su existencia en Castilla, también está comprobada, al menos en las grandes juderías como Sevilla y Toledo. Vid. CANTERA Burgos, F., "Cofradías judías en Zaragoza», Sefarad, VII (1947), págs. 369-371. MADURELL y MARIMON, J. M., «La cofradía de la Santa Trinidad de los conversos de Barcelona», Sefarad, XVIII (1958), págs. 60-82. Blasco MartíneZ, A., «Instituciones sociorreligiosas judías de Zaragoza (siglos XIV-XV). Sinagogas, cofradias y hospitales», Sefarad, XLIX (1989), págs. 227-236 y L (1990), págs. $3-46$ y 265-288. 
Un conocido «responsa» ${ }^{6}$ de Salomón Ibn Adret resume los tipos de gobierno posibles en las aljamas a mediados del siglo XIII:

«Hay lugares donde todos los asuntos los llevan los ancianos y consejeros; otros donde incluso la mayoría carece de autoridad para hacer nada sin el consejo y el acuerdo unánime de toda la comunidad, y otros en fin donde designan a unos hombres conocidos para que por cierto tiempo les gobiernen y administren sus asuntos generales»?

Neuman clasificó estos tres tipos como: régimen comunal y primitivo, régimen oligárquico, y régimen electivo ${ }^{8}$, lo que obedecía a una lectura poco crítica del texto. En realidad, Ibn Adret está haciendo una justificación del régimen de gobierno de la aljama de Zaragoza, que como sabemos tuvo un carácter oligárquico y electivo ${ }^{9}$, y que por esta época se iba extendiendo a otras comunidades.

No parece muy seguro que, en origen, el régimen de las aljamas tuviese un carácter comunal. De hecho no se constata en ninguna judería de Castilla la existencia de una institución que consista en la reunión de todos los vecinos en la sinagoga con fines deliberantes o ejecutivos. Sin embargo, algunas prácticas religiosas dejan abierta esta posibilidad. En el siglo XIII, el régimen de las aljamas que se conoce, con más detalle en el área aragonesa ${ }^{10}$, tiene a su frente a un consejo de ancianos, el cual nombra a su vez a un número variable de adelantados (mucaddemin) y jueces (dayyamin). También se nombraba al bedin, un funcionario público que actuaba como fiscal de la comunidad y dirigía a la policía. Por último, el rey, o el poder señorial en la zona, podía designar al rab de la comunidad o del territorio. Dado el carácter religioso del cargo, y la autoridad moral que ejercía sobre el conjunto de la aljama, el rab debía ser una persona virtuosa y versada en el Talmud-Torah, circunstancias que no siempre concurrían en el designado. La propia definición institucional del régimen de las aljamas en esta época muestra el ascenso de las

- Es conocida la importancia de los «responsa», respuestas de rabinos de prestigio a preguntas formuladas por las aljamas sobre diversos hechos. Una relación de los más importantes en LAREDO, D. I., "Las seelot $u$ tesubot como fuente para la historia de los judíos españoles", Sefarad, V (1945), págs. 441-456.

7 IBN Adret, Responsa, vol. Vll, n.. os 394-399-428, apud. Baer, Historia, I, pág. 176.

8 NEUMAN, op. cit., vol. l, págs. 34 y ss.

9 VendRELL de Millas, F., «Al margen de la organización de la aljama judaica de Zaragoza», Sefarad, XXIV (1964), págs. 81-106.

${ }_{10}$ La primera takkanot que se conoce es la de Calatayud, del año 1229. BAER, F., Die juden im Christlichen Spanien, Erster Teil: Urkunden und Regesten. I. Aragonien und Navarra, doc. n. ${ }^{\circ} 88$. Berlín 1929. 
oligarquías, que se adueñaron del consejo de ancianos, y se turnaron en el desempeño de los cargos de gobierno más importantes.

Cada aljama era autónoma, característica que en Aragón se acentuó en los siglos XIV y XV. En Castilla, en cambio, las cosas evolucionaron de forma diferente. A lo largo del siglo XIII, el régimen oligárquico mencionado se impuso primero en las grandes aljamas, como Toledo. Desde éstas, se difundió a las pequeñas aljamas de las zonas rurales, en un proceso que puede considerarse de imitación; pero que, al mismo tiempo, evidencia una clara influencia de las grandes aljamas sobre las pequeñas. En cualquier caso, resulta evidente que los representantes de las aljamas se reunían para distribuir el importe de los tributos recaudados por la corona sobre las juderías. La primera noticia de este hecho aparece en el preámbulo del padrón de Huete de $1290^{11}$. Como en el caso de los representantes de las ciudades en las cortes, a estas asambleas acudían sólo adelantados o secretarios de las aljamas más importantes. En algunos casos, varias aljamas pequeñas se reunían para tributar conjuntamente, lo que se denominaba "collecta». Las pequeñas comunidades no estaban representadas; aunque sí tributaban junto con la aljama más grande de su territorio. Esta dependencia fiscal se tradujo a menudo, también, en una dependencia jurisdiccional y religiosa. El fuero de los judíos de Sahagún, del año 1255, dispone que los adelantados de esta aljama fuesen nombrados por los rabinos de Burgos, y jurasen fidelidad al abad del monasterio, que era el señor del lugar ${ }^{12}$.

Si el régimen de adelantados conducía a una pérdida efectiva de la autonomía de la aljama, no es menos importante señalar que, las relaciones de poder en el seno de la oligarquía judía estaban favoreciendo el ascenso de una élite cortesana, vinculada a los grandes negocios crediticios y de arrendamiento de impuestos. Esta élite, que también existía en el entorno de los grandes poderes señoriales, como era el caso del obispo de Toledo, dirigía la política fiscal judiega y actuaba como instancia de apelación en lo judicial. Sin embargo, su prestigio religioso era nulo por desenvolverse en un ambiente de corrupción material. Ella fue el instrumento utilizado para acabar con la autonomía de las aljamas. Desde mediados del siglo XIV se conoce la existencia de la figura del rab de la corte. Una especie de gran rabino de todas las comunidades judías del

\footnotetext{
11 Publicado por Carrete Parrondo, C., «El repartimiento de Huete de 1290", en Sefarad, XXXVI (1976), págs. 121-140. Vid. nuestro comentario en "Juderías y aljamas en el mundo rural de la Castilla Medieval», en Judios y conversos en la Historia (en prensa).

12 BAER, F., Die Juden..., op. cit., Zweiter Band. Kastilien/Inquisitionsakten, doc. n. ${ }^{\circ} 70$. Berlín 1936. En adelante, esta obra se citará indicando sólo el autor, volumen y $n .^{\circ}$ de doc.
} 
reino, nombrado por el monarca. Entre sus atribuciones está la de ratificar las decisiones más importantes tomadas por cada aljama. El caso de Yosef Pichón, contador mayor de Enrique II, puede ilustrar las tensiones entre las aljamas y la corte. Coincidiendo con la muerte del monarca, y el inicio del reinado de Juan I. Yosef Pichón fue acusado de malsín y un tribunal de la aljama de Burgos ordenó su ejecución. Una vez conocido el hecho, el rey decretó la supresión de la autonomía jurisdiccional de las aljamas de Castilla ${ }^{13}$. Otro caso claro de injerencia externa en la aljama es el del arzobispado de Toledo. Una primera noticia de los conflictos habidos por esta causa se fecha en 1388 , cuando el obispo D. Pedro Tenorio comunicó a las aljamas del obispado que el rabino mayor nombrado por éstas, Çulema Alfahar, había sido depuesto por residir habitualmente en Sevilla. En su lugar, el obispo nombró a su médico particular, el rabí Hahym. En 1395, nuevamente, D. Pedro Tenorio nombró a su físico, en este caso el maestre Pedro, para el cargo de alcalde y juez mayor de todas las aljamas del obispado. Ahora se trataba de un cristiano, esto es lo más probable, en aplicación del sistema de jueces apartados para los judíos. El nombramiento no era del agrado de las aljamas. Una de sus primeras actuaciones, ante la aljama de Alcalá de Henares, fue contestada, organizándose un tumulto en la sinagoga, en el que una parte se negaba a reconocerlo, mientras que otra, a voces, acataba el nombramiento ${ }^{14}$. Finalmente, las ordenanzas de Valladolid de 1412 suprimieron la autonomía de las aljamas. El artículo séptimo de las mismas dispone a este respecto:

"Otrosy que las aljamas de los judios e moros de los mis regnos e sennorios non puedan aver nin ayan de aqui adelante jueses judios nin moros entre si, para que les libren sus pleitos, asy ceviles como criminales... e mando que sean librados de aqui adelante los tales pleitos... por los alcaldes de las cibdades e villas e lugares donde moraren ${ }^{15}$.

Después, aunque las takkanot de Valladolid de 1432 restauraron parcialmente el régimen de las aljamas, éstas no recuperaron la autonomía jurisdiccional, sino que se mantuvieron en una dependencia estrecha de la figura del rab de la corte. No en vano fue el propio rab de la corte, $D$. Abrahan Benveniste el artífice de esta reforma.

La aljama desarrolla su actuación en tres áreas principalmente: fiscal,

13 Baer, F., Historia..., op. cit. I, pág. 305.

14 Sobre el caso Toledano, vid. BAER, II, docs. n.. ${ }^{\text {os }} 241,244$ y 258.

15 BAER, II, doc. $n .^{\circ} 275$. 
jurisdiccional y religiosa. Esto no quiere decir que hubiese funcionarios especializados en cada una de ellas; por el contrario, y al igual que ocurre en la administración concejil, parece que hubo un gran sincretismo e indefinición en la atribución de funciones a los oficiales, sobre todo en las aljamas más pequeñas.

\section{LA ORGANIZACIÓN FISCAL}

Los asuntos fiscales constituían un área de clara separación entre la población cristiana y la judía de un mismo lugar. En principio, los judíos tenían un régimen tributario apartado, por lo que no contribuían con el resto de los vecinos en el mantenimiento de las murallas, $u$ otros asuntos de interés común. Sin embargo, propiedades sujetas al pago de tributos vecinales eran enajenadas entre cristianos y judíos con cierta frecuencia, por lo que, finalmente, se llegó a establecer un régimen fiscal común en determinadas circunstancias. Hay algunos casos conocidos en los que los rerpresentantes de la aljama y los del concejo llegan al acuerdo de colaborar en las obras públicas de la villa. Por ejemplo, el acuerdo alcanzado en Palencia, el año 1194, por el que se aprueba que los judos y moros de dicho lugar pechen conjuntamente con los cristianos en las facenderas, pechos y obras del muro y vallas ${ }^{16}$. Pero no se puede decir que esto fuera lo más frecuente. Por el contrario, abundan los ejemplos que demuestran el mantenimiento de la tributación separada ${ }^{17}$. Además, en los lugares de señorío se les obligaba a pagar un tributo especial por el hecho de ser judíos ${ }^{18}$.

El régimen fiscal era gravoso, y pudo llegar a ser asfixiante a finales del siglo XIV. Desde luego, la situación económica de las aljamas no era muy diferente de la del resto de los concejos. La presión señorial, más que la de la corona, era excesiva. El sistema de encabezamiento tributario de cada aljama, para su distribución posterior por individuos, permíía una manipulación abusiva por parte de los más poderosos. Éstos no sólo hacian recaer la mayor parte de los tributos sobre los más débiles; a menudo, también, conseguían privilegios de exención tributaria de la corona. En las cortes de Valladolid de 1312, los representantes de las al-

16 BAER, II, doc. n. ${ }^{\circ} 41$. No es el único caso documentado.

17 En Pancorbo, en 1271, los judíos tributaban la martiniega, fonsadera infurción y otros pechos por separado. Cfra. BAER, II, doc. $n .^{\circ} 74$. En Albelda, en 1285, la aljama pagaba por separado la fonsadera. Ibidem, n. 89.

${ }_{18}$ Así aparece en el fuero de los judíos de Sahagún de 1255 , BAER, II, n. 70 , o en Oña en 1381, ref. AHN, Clero, carpeta 315 , doc. n. ${ }^{\circ} 14$. 
jamas se quejaron de la existencia de más de cinco mil judíos excusados, según privilegios concedidos por Alfonso $X$ y Sancho IV ${ }^{19}$. Posiblemente era una exageración, pero el problema fue en aumento, al menos hasta la crisis de 1391. En el momento de redactarse las ordenanzas de 1432, esta cuestión seguía preocupando a los representantes de las aljamas. EI capítulo cuarto de las mismas, titulado Sobre el negocio de los tributos e serviĩos, aborda esta cuestión. En él se determina que no haya más exenciones de tributos que aquellas que cuenten con privilegios reales al efecto y estén reconocidos por el rab de la corte. Se prohíbe expresamente que los judíos, por separado, acudan a solicitar tales privilegios y, asimismo, que los habitantes de una judería vayan a otra, de señorío, en busca de condiciones fiscales más favorables. Por último se dispone que los tributos sean asignados y recaudados con justicia, de acuerdo con las disposiciones dictadas por el rab de la corte ${ }^{20}$.

Además, la aljama imponía otros tributos de carácter interno, destinados al mantenimiento de la sinagoga, el midrash, huérfanos, viudas y rabinos dedicados al estudio de las Sagradas Escrituras. La asignación del tributo se hacía por un sistema de capitación directa. Sin embargo la comunidad estaba dividida entre los más ricos, que preferían un sistema de tallas iguales para todos, y el resto de los vecinos, partidarios de distribuir los tributos según la riqueza de cada uno, en función de la declaración presentada ante los oficiales de la aljama en el momento de realizar el padrón (pinkas). Ante las dificultades que presentaba cualquiera de los dos sistemas para su recaudación, y el empobrecimiento progresivo de las aljamas, sobre todo después de 1391, se adoptó el tributo denominado "nebda", que introducía el sistema de sisas. De forma indirecta, se recaudaba un tributo sobre la carne y el vino vendido en la judería ${ }^{21}$, e incluso en algunos lugares se llegó a contribuir con las sisas en la cabeza del pecho ${ }^{22}$. La tributación indirecta o sobre el consumo, ya era aplicada en el conjunto del reino desde la implantación de la alcabala en tiempos de Alfonso XI y Enrique II. Sin embargo, la recaudación de un tributo específico de este tipo dentro de la comunidad judía, afectaba negativamente a los precios del mercado, en donde concurrían conjuntamente con los cristianos. Las ordenanzas de 1412, de fuerte contenido

19 BAER, $11, n .^{\circ} 132$.

20 Ordenanzas de Valladolid de 1432, publicadas por FERNÁNDEZ Y GONZÁlez, «Ordenamiento formado por los procuradores de las aljamas hebreas pertenecientes al territorio de los estados de Castilla, en la asamblea celebrada en Valladolid el año 1432", BRAH, VII y VIII (188586), págs. 145-189, 275-305, 395-413 y 10-14.

21 Ibidem, caps. I-VII, pág. 178.

22 Por ejemplo, en Segovia en 1409. Cfra, BAER, $11, n .{ }^{\circ} 274$. 
antijudío, según hemos comentado, disponen que las aljamas «...no sean osadas de hechar nin echen pecho nin tributo alguno entre sy nin pongan inposycion en cosa alguna». Más adelante añade la prohibición de realizar derramas de pechos, excepto en el caso de los servicios reales, o de recaudar una cantidad superior a la debida a la Corona ${ }^{23}$. Estas medidas pueden ser consideradas como una agresión a los privilegios de la población judía, en tanto que se oponen a la existencia de una organización fiscal propia en el seno de la comunidad, y realmente tuvieron consecuencias muy negativas para ésta. Sin embargo, resulta evidente que la evolución de la sociedad y las nuevas prácticas económicas, hacían cada vez más difícil el mantenimiento de áreas apartadas, y exigían, por el contrario, una mayor uniformidad en el régimen tributario. No es necesario decir, una vez más, que se observa esta misma tendencia en los concejos.

\section{EL RÉGIMEN JURISDICCIONAL}

En el orden jurisdiccional, la aljama contaba con sus propios tribunales cuya competencia se extendía exclusivamente sobre los miembros de su comunidad. Los jueces, dayyamin, eran nombrados entre los vecinos por elección o designación. A veces la designación de los jueces correspondía a instancias ajenas a la propia aljama, pudiendo ser el rab de la corte, el rey o el poder señorial de la zona. La justicia aplicada era la Torah, por lo que tenía un carácter sagrado; sin embargo, los delitos juzgados podían ser indistintamente de índole civil, penal o religiosa. Los especialistas han señalado una mayor evolución de la jurisprudencia en materia civil, precisamente porque, en este apartado, la Torah es menos explícita. Ello posibilitó una mejor adaptación de los tribunales a la evolución general de la sociedad, mientras que en los asuntos penales y religiosos se mantuvo una mayor rigidez. Cabe pensar que este hecho provocara una acentuación de las tendencias segragacionistas en la población judía, en tanto que reforzaba sus señas de identidad.

Los pleitos mixtos, y hay que tener en cuenta que los más frecuentes fueron los relacionados con las deudas, planteaban una colisión de derechos entre los propios de la aljama y los del concejo. A este respecto, resulta evidente que la jurisdicción cristiana fue limitando el campo de actuación de los tribunales de las aljamas, lo que constituye un ejemplo más del deterioro progresivo de los privilegios judíos en el reino. Un caso

23 BAER, II, n. ${ }^{\circ} 275$, puntos 8 y 9. 
que muestra las tensiones existentes en relación con el mantenimiento de la jurisdicción privativa para los judíos, lo tenemos en la villa de Ocaña. A fines del siglo XIII, Fernando IV autorizó al comendador de Ocaña a aplicar el Fuero Juzgo en esta población, incluidos los judíos del lugar. En 1327, la aljama y el concejo de esta villa ratificaron una avenencia que establecía un régimen mixto y derogaba la orden anterior ${ }^{24}$. En general, a lo largo del siglo xIV, las aljamas contaron con jueces propios para sus asuntos internos, y jueces cristianos para los pleitos mixtos. Para los casos de deudas había porteros de las aljamas encargados de ratificar las cartas de préstamo, y entregadores que ejecutaban las confiscaciones de bienes por deudas impagadas ${ }^{25}$. Las referencias documentales al respecto son muy abundantes. Quizás la más representativa, por su carácter emblemático para otros lugares, sea la orden dada por la reina D. ${ }^{a}$ María contra la aljama de Valladolid, el año 1304, por la que dispone que las entregas se hagan ante los alcaldes del concejo, y la toma de bienes de los deudores sea ejecutada por los merinos ${ }^{26}$. En el resto de los asuntos relativos a la jurisdicción, se tendió a la implantación de los llamados jueces apartados. Este sistema, consistente en que uno de los jueces del concejo se ocupara especialmente de los asuntos judíos, supuso en realidad una supresión paulatina de la autonomía jurisdiccional de las aljamas. La orden citada de 1304 para Valladolid, y otra de 1305 para León, establecen que cuando el rey ponga jueces de fuero en dichas ciudades, los judíos de sus aljamas puedan elegir a uno de estos jueces para que juzgue los pleitos mixtos ${ }^{27}$.

El paso siguiente fue la supresión progresiva de la autonomía de las aljamas en los asuntos internos. Las leyes de Soria de 1380 suprimieron las competencias de sus tribunales en delitos penales. Un asunto clave en esta materia era el de los malsines. Los delatores de los judíos ante los tribunales cristianos destruían la cohesión del grupo. A menudo, la causa original del enfrentamiento era de naturaleza económica, como diferencias surgidas en el reparto de tributos, por ejemplo. Pero las acusaciones hechas por los malsines tenían un contenido religioso principalmente. La sentencia contra Josef Pichón, que hemos comentado más arriba, mostró con claridad hasta dónde se podia llegar en esta cuestión.

24 BAER, H. ח.. ${ }^{\text {os }} 105$ y 151.

25 Un caso que ilustra con claridad la actuación de estos oficiales y el procedimiento de subasta seguido para la ejecución de las deudas, lo tenemos en Oña el año 1381, septiembre 30. Ref. AHN, Clero, carpeta 315, doc. n. 10.

26 BAER, $11, n \cdot{ }^{\circ} 118$.

27 BAER, II, $\mathrm{n} .^{\circ}$ 119. También se registra la existencia de jueces apartados en Belorado en 1325. Ibid., n. ${ }^{\circ} 112$. 
La corona, consecuentemente, impuso una nueva limitación con respecto a los derechos jurisdiccionales de las aljamas. En adelante, sería la justicia real la encargada de recibir en apelación y ejecutar las condenas dictadas por los tribunales judíos. Las ordenanzas de 1412 suprimieron completamente la existencia de tribunales judíos incluso para asuntos internos ${ }^{28}$. Por último, las ordenanzas de 1432 restablecieron los tribunales judíos y regularon todo lo relativo a los malsines. En definitiva se impuso un sistema de jueces electivos de duración anual, cuyas sentencias podían ser vistas en grado de apelación ante el rab de la corte ${ }^{29}$. Por lo tanto, fue esta figura, evidentemente próxima a la corona, la que conservó la antigua autonomía jurisdiccional de las aljamas. En Aragón, un intento similar llevado a cabo por la reina $D .{ }^{a}$ Violante el año 1390 fue rechazado y fracasó.

\section{LA ORGANIZACIÓN RELIGIOSA}

Los asuntos religiosos constituyen el elemento diferencial por excelencia entre las comunidades judías y cristianas. El Judaísmo tiene su fundamento en la Torah, y ésta, a su vez es considerada la base del mundo. Cualquier otro aspecto de la realidad, incluido el orden político y social, está supeditado a la Ley Sagrada:

«Judio es dicho aquel que cree et tiene la ley de Moysen, segunt que suena la letra della, et que se circuncida et face las otras cosas que manda esa su ley...

Sinagoga es lugar do los judios facen oracion...

Sabado es dia en que los judios facen sus oraciones et estan quedados en sus posadas et non se trabajan de facer merca nin pleyto ninguno...".

Estos párrafos de Las Partidas (VII, 24, 1-4-5) resumen los tres rasgos distintivos del judaísmo en la España Medieval, y posiblemente también en cualquier otro lugar y tiempo: una ley, un edificio sagrado, centro de reunión, y una festividad semanal que imponen una forma de vida diferenciada, incluso en los aspectos más cotidianos.

La sinagoga es el centro de reunión de la comunidad. No es sólo un templo. En ella se asienta el tribunal de la aljama, y sus sótanos sirven,

28 Vid. punto 7 de dichas ordenanzas. Ibid., nota 15.

29 Ordenanzas de 1432. Cap. II "Sobre el asunto de elección de Dayanes y otras autoridades», y cap. III «Sobre negocio de traiciones». FERNÁNDEZ Y GoNZÁlEZ, op. cit., págs. 275 y ss. y 289 y ss. 
a veces, de cárcel. También es un centro de actividad económica. Aquí se publican las derramas de tributos, se custodian los padrones, se ratifican los préstamos y se decretan las confiscaciones. Pero sobre todo, la sinagoga es un centro de estudio del Talmud-Torah y de oración. La «midrash», o aula de estudio, era una dependencia habitual en las grandes y pequeñas sinagogas. Algunas llegaron a especializarse como «Bet haMidrash", o casas de estudio, frente a las "Bet ha-Keneset», o casas de oración ${ }^{30}$. De todas formas, la tradición que ligaba al estudio con la oración se mantuvo, y la presencia de rabinos y maestros de la Ley de gran prestigio en las pequeñas juderías de las zonas rurales fue relativamente frecuente, sobre todo a partir del siglo XIV, cuando se inició el declive de las juderías. Frente a esto, puede constatarse cómo las autoridades cristianas se opusieron al crecimiento de las sinagogas, como un elemento más de su política antijudía. Ya en Las Partidas se contienen disposiciones contrarias a la construcción de nuevas sinagogas o a la ampliación de las existentes. Las predicaciones de Ferrand Martínez se dirigían contra éstas, proponiendo su transformación en iglesias. Y las violencias antijudías de 1391 tuvieron como objetivo prioritario el incendio o destrucción de las sinagogas. Por su parte, las comunidades judías se aferraban a su mantenimiento, identificando la existencia de la judería con la permanencia de la sinagoga. Para ello se hacían aportaciones económicas, donaciones y fundaciones, al modo de las capellanías cristianas ${ }^{31}$. De esta forma, la sinagoga disponía de un patrimonio de bienes muebles e inmuebles con cuyos beneficios financiaba el mantenimiento de los maestros de la ley y de las universidades (midrash) y escuelas.

La violencia antijudía de fines del siglo XIV y principios del XV tuvo como objetivos prioritarios, en materia religiosa, la supresión de determinadas prácticas, como el rezo de la oración de los herejes (birkat haminim) ${ }^{32}$, evitar la contaminación de los cristianos mediante la adopción de medidas segregacionistas, y proteger y vigilar a los conversos para evitar que se tomasen represalias contra ellos, o bien que judaizaran en secreto ${ }^{33}$. Las predicaciones de Vicente Ferrer contenían un mensaje de intolerancia religiosa radical al proponer la conversión forzosa de los judíos al cristianismo. La doctrina oficial de la Iglesia era contraria a este

30 Neuman, op. cit., págs. 146-160.

31 Vid., la fundación de Rabí Yocef el Leví en Écija en 1332. Crra. BAER, II, n. 157.

32 La supresión de esta oración y la quema de libros sagrados que la contuvieran fue aprobada en las Cortes de Soria de 1380 . El asunto ya venía de antes y se recoge también en Las Partidas.

33 Las ordenanzas de 1412 no se refieren para nada a las aljamas; pero sí se ocupan de los contactos entre judios y cristianos - puntos 1 y 4 - y de los conversos --punto 3 - 
tipo de conversiones; sin embargo, en la práctica, las propiciaba ${ }^{34}$. Es sabido que las órdenes mendicantes, principalmente los dominicos, predicaban en las sinagogas, y que la asistencia a estos actos era obligatoria para los judíos. La corona se oponía a ello porque constituía una provocación que, a menudo, terminaba en tumultos y violencias. El año 1383, Juan I ordenó al arcediano de Écija que cesara en sus predicaciones ${ }^{35}$. Como es bien sabido, la orden real no fue respetada. En 1392, Enrique III ordenó al concejo de Burgos que impidiese que «los christianos - ylos conversos les fagan (a los judíos) alguna syn rason ni los premien, por que se tornen christianos contra su voluntad» ${ }^{36}$. Las ordenanzas de 1432 contienen un primer capítulo dedicado a las sinagogas y a los centros de estudio de la Torah, que se inscribe en la línea de protección real ya mencionada. Sin embargo, la cuestión de los conversos fue creciendo en importancia hasta llegar a convertirse en un elemento de intransigencia. La sentencia estuvo de Pero Sarmiento, del año 1449, muestra la preocupación existente por la contaminación religiosa de los conversos. El asunto siguió perturbando a la sociedad y, como es sabido, apareció nuevamente para justificar el decreto de expulsión de 1492.

\section{LA JUDERIA}

Pasamos a continuación a analizar las características físicas del barrio judío, que es la realidad urbana y social que representa la aljama. En este punto, el investigador dispone de una gran cantidad de trabajos que informan sobre las juderías castellanas consideradas por separado o en conjuntos territoriales más extensos ${ }^{37}$. En ello pueden encontrarse descripciones y comentarios sobre los elementos más característicos de las juderías, como la sinagoga, la carnicería, el mercado, el fonsario, las murallas, etc. Por ahora, vamos a centrarnos en una exposición sintética de

${ }^{34}$ Un ejemplo de la tolerancia encubierta con respecto a las conversiones forzosas lo tenemos en la sentencia absolutoria de excomunión, dictada por el cardenal D. Guido, legado de Benedicto XIll en Avignon, en favor del abad del monasterio de Sahagún y tres monjes de esta comunidad. Éstos habían acogido, en 1349, al presbítero Johan Martínez de Balvás, perseguido por la justicia real por sus predicaciones a los judíos y haberles forzado a la conversión. La bula es del año 1403, y se justifica porque el abad, simplemente, había defendido el derecho de inmunidad del monasterio en este caso. BAER, II, $n .{ }^{\circ} 265$.

35 BAER, ll, n. ${ }^{\circ} 221$, pág. 215.

36 BAER, II, n. 254.

37 La bibliografía al respecto es extensísima, para evitar una cita detallada, remitimos a la serie publicada en la revista Sefarad, desde su aparición hasta la actualidad. Por nuestra parte, queremos reconocer la deuda contraída con todos estos trabajos, cuyas ideas manejamos a lo largo del nuestro. 
las formas de residencia de los judíos en las villas castellanas, para señalar, a continuación, las tendencias evolutivas que se aprecia en las mismas.

Naturalmente, las formas de residencia dependieron, en mayor o menor grado, del tipo de convivencia o rechazo existente entre las dos comunidades. La sociedad cristiana, con los instrumentos de poder que tenía en su mano (corona, iglesia, nobleza), partía de un supuesto de superioridad de su fe sobre cualquier otra religión, incluido el judaísmo ${ }^{38}$. La tolerancia o la protección de las minorías religiosas se hizo siempre desde la base de la sumisión. Por este motivo, cuando las tendencias antijudías cobraron fuerza, para nosotros desde finales del siglo XIII, el deterioro de la convivencia condujo a un aislamiento progresivo de la población judía, lo que puede considerarse como un resultado deseado de forma recíproca por ambas comunidades. La legislación alfonsí, o el sínodo y las cortes de Zamora de 1313, por citar sólo los textos más generales, contienen disposiciones encaminadas a impedir el contacto cotidiano y cualquier exceso en la convivencia entre cristianos y judíos. En las grandes ciudades, las juderías contaban con uno o más barrios en donde se concentraba la población judía. La lectura de algunos documentos permiten afirmar que estos barrios no formaban un ghetto propiamente; sino que en los mismos residían también otras familias cristianas en mayor o menor número. No obstante, la presión social llevó a una acentuación de las características judías de estos barrios en ciudades como Sevilla y Toledo, lo que se convirtió en un modelo a imitar en otros lugares y también en las pequeñas juderías de las zonas rurales. Desde luego, el apartamiento de los judíos en barrios separados nunca se llevó a efecto de forma general. A mediados del siglo xIV. Pedro I revisó algunos acuerdos tomados por su predecesor Alfonso XI a este respecto. En concreto dispuso que, en aquellos lugares en donde hubiera avenencia para que los judíos vivieran en barrios separados, esto se pudiera mantener; dando a entender que la separación fuera resultado de un acuerdo tomado libremente por las dos partes ${ }^{39}$. Sin embargo, más adelante se refiere a una realidad bien distinta, como es el hecho de que los cristianos alquilaran casas a los judíos en sus lugares de residencia ${ }^{40}$.

\footnotetext{
38 Una declaración caracteristica puede verse en Las Partidas (1, 4, 119 (63)) cuando ordena que los judíos se humillen ante el «Corpus Christi» cuando se encuentren con él en la calle «...asi como lo facen los christianos, "porque esta es la verdat et otra non..."».

39 BAER, II, n. ${ }^{\circ} 181$.

40 Ibidem, punto 71.
} 
La historiografía especializada ha señalado la gran dispersión del poblamiento judío en el reino de Castilla. Los repartimientos fiscales del siglo $x v$ mencionan cerca de cuatrocientos lugares diferentes en los que habitan judíos. En una gran proporción se trata de pequeñas juderías, en las cuales, las relaciones entre judíos y cristianos se desenvolvían en un marco vecinal y aldeano mucho más permeable que el existente en las grandes ciudades. Las viviendas de los judíos podían concentrarse en una determinada zona de la villa, a veces en las inmediaciones de un edificio, como la iglesia o el alcázar, o cerca de un lugar como la plaza o los soportales de la calle principal en donde se localizaba el comercio; en definitiva, buscando la proximidad de elementos o espacios urbanos que actuaran como referencia centralizadora de la vida vecinal. En estos casos, el estudio detallado de la documentación, y nosotros lo hemos podido realizar personalmente en Briviesca, Oña, Pancorbo, y algunos otros lugares del norte de la actual provincia de Burgos ${ }^{41}$, muestra que junto a las viviendas de los judíos se encontraban otras habitadas por cristianos, y que todas integraban un conjunto abigarrado, muy característico del urbanismo medieval.

La tendencia a concentrarse en los alrededores del alcázar, o incluso en su interior, es más frecuente en las juderías de tamaño medio, y en algunos casos en las grandes como Burgos. Se documenta, entre otras, en Oviedo en 1274 y en Cuenca en $1363^{42}$. En otras ocasiones, los barrios judíos se rodeaban con una cerca que los separaba del resto de la población cristiana. En estos hechos había un doble objetivo, por una parte estaban las razones de seguridad frente a posibles ataques, por otra un indudable interés de control fiscal por parte de la corona. Pero la fortificación de los barrios judíos era vista con desconfianza, sobre todo en momentos como la guerra civil de 1366-99. En 1367, las cortes de Burgos solicitaron de Enrique II que no lo permitiera, pero el monarca lo recha$z^{4}{ }^{43}$. La tendencia general, en cualquier caso, fue hacia la ruptura de estos núcleos fortificados. En ocasiones por medios jurídicos, pues los reyes exigieron de las aljamas, cuando las juderías se encontraban en el interior de un castillo, el compromiso de no proteger a los malhechores que se refugiaran dentro, y permitir la entrada de los merinos y otros oficiales de la justicia real cuando fueran en su persecución ${ }^{44}$. Otras veces

41 Vid., nuestro trabajo Las aldeas castellanas en la Edad Media. Madrid 1990, passim.

42 BAER, II, n. ${ }^{\circ} 83$ y 200.

43 BAER, II, n. 205.

44 El Libro de los Fueros de Castilla contiene las siguientes disposiciones a este respecto: «Et sy demanda el meryno al judio calonnyas o otra cosa o mal fechores que an en su castiello, et nombrar quien son, e quel den las llaves del castiello, que non se ayan, deven le dar las llaves e catar los luego». 
son meros cambios en las ordenanzas urbanas sobre edificios. Por ejemplo, en Sevilla, una ordenanza prohibía la contrucción de casas o edificios «... tan alto nin mas que la cerca de la judería desta cibdad hasta un tiro de ballesta...». Esta medida, cuya finalidad era principalmente defensiva, fue derogada por otro privilegio de Enrique II, fechado el año $1371^{45}$.

La medida del apartamiento de los judíos fue madurando progresivamente a lo largo del siglo XIV. Finalmente, las ordenanzas de Valladolid del año 1412 la decretaron en su punto primero:

«Primeramente, que de aquí adelante todos los judios e judias e moros e moras de los mis regnos e sennorios sean e bivan apartados de los christianos e christianas en un lugar e parte de la cibdat o villa o lugar donde fueren vesinos, e que sean cerradas las calles e las puertas en derredor, en guisa que todas las puertas salgan al dicho cerculo, e que el dicho cerculo aya una puerta, por do se mande, e non mas, e que en el dicho cerculo moren los dichos judios que en el dicho sten, e (en el) cerculo que les asy fueren asygnado moren los tales judios e judias e moros e moras e non en otro lugar nin casa fuera del» ${ }^{46}$.

Dicha medida encerraba grandes dificultades para su aplicación de forma inmediata, entre otras cosas, porque venía a continuación de las destrucciones habidas en 1391. Una judería rica, como la de Valladolid, arrendó en 1413 los terrenos para la construcción de la nueva judería. El contrato de alquiler preveía una reducción del importe de la renta en un 12,5 por 100 durante los primeros cuatro años, y además contenía una cláusula de condonación de obligaciones para los contratantes en los siguientes términos: «...pero sy nuestro sennor el rey o otra persona qual quier que poderio aya nos mandare despoblar la dicha judería e poblar la en otra parte e cabe e se tornaren los judios della todos christianos, en tal manera que no aya judio alguno vezino de la dicha villa para la poblar, que no sea mas tenudo de pagar renta ni alquile alguno por el dicho suelo..." ${ }^{47}$. La judería de Sevilla, tal y como se describe en un documento de 1437, posterior por tanto a la orden de Juan II de supresión de las ordenanzas de apartamiento, presentaba problemas similares. Se constata la existencia de judíos «...que moran fuera de los apartamientos...» en casas alquiladas a los cristianos. Por su pobreza, no pueden arrendar o construir otras casas en la judería. En ésta, donde viven los demás judíos, «...e aun algunos christianos...» hay una situación de su-

45 BAER, II, n. ${ }^{\circ} 216$.

46 BAER, II, n. ${ }^{\circ} 275$.

47 BAER, ll, n. 281. 
perpoblación, que hace subir el precio de la vivienda, pues «...non ay lugar donde pudiesen caber todos...», por lo que se solicita la ampliación del barrio judío por sus aledaños ${ }^{48}$. Vistas las dificultades existentes para la creación de barrios judíos apartados, es comprensible que en la mayor parte de las pequeñas juderías ni siquiera se intentara. En Oña, por ejemplo, los judíos que regresaron varios años después de las persecuciones, volvieron a comparar las mismas casas en donde moraron sus antecesores, junto a las viviendas de los otros vecinos cristianos. Es posible concluir, pues, que en Castilla no hubo auténticos ghettos judíos, y esto quizás fuera un elemento de debilidad en los momentos difíciles que se vivieron al final de la Edad Media.

\section{LAS FORMAS DE CONVIVENCIA}

Por último, vamos a comentar cómo fue la convivencia cotidiana en las aljamas. Para ello es necesario tener en cuenta que, aunque la tendencia general fue la expuesta hasta ahora, en cada lugar hubo un mayor - menor grado de entendimiento, en función de factores personales que a nosotros se nos escapan, por no ser recogidos por las fuentes. Así fue posible la existencia de situaciones dispares, como la de Palencia, en donde el concejo afirmaba que los judíos vivían en «vecindad» con el resto de los vecinos y pagaban los tributos conjuntamente con ellos; y, en sentido contrario, la de Logroño, en donde la división entre judíos y cristianos era tan tajante, que la aljama acordó pagar al concejo un tributo de 200 mrs anuales, además de los otros tributos acostumbrados, y a cambio quedar exentos de colaborar en trabajos comunes, como reparar muros y puentes, limpiar ríos o construir diques ${ }^{49}$.

Resulta evidente que las diferencias religiosas impedían una convivencia normal, y no nos referimos sólo a la falta de tolerancia en cuestiones de fe. Por ejemplo, la estricta observancia del sabat suponía la existencia de un ciclo semanal diferente entre judíos y cristianos. Las Partidas piden que se respeten estas costumbres, y que los judíos no sean citados a declarar ante los tribunales los sábados. Pero esto no era suficiente. Resultaba que los domingos los judíos realizaban trabajos, y esto, que era públio, podía ser considerado una afrenta por los cristianos. En las cortes de Valladolid de 1351, Pedro I ordenó que si los menestrales y comerciantes judíos trabajaban los domingos, lo hicieran a puerta cerrada para

48 BAER, II, n. ${ }^{\circ} 291$.

49 BAER, II, n.. ${ }^{\circ} 120$ y 180. 
evitar el escándalo. También se exigió respeto a las ceremonias religiosas cristianas y sobre todo que se ocultaran en momentos graves como la festividad del Viernes Santo o cuando se organizaran prerrogativas por epidemias $u$ otras calamidades.

En el ámbito de las relaciones económicas, los contactos fueron más fluidos. No nos vamos a referir en este momento a la cuestión de los préstamos, práctica que persiste hasta la expulsión a pesar de su proscripción ${ }^{50}$. Si nos fijamos en los mercados, se aprecia un claro deseo de atraer a los judíos para que participen en los mismos. En Brihuega, el obispo de Toledo D. Pedro Tenorio ordenó que el mercado semanal que tenía lugar los sábados se trasladase al miércoles uporque el dicho dia sabado, judios algunos non pueden venir..., seyendo ellos uno del gran meneo del dicho mercado" ${ }^{51}$. La presencia de los judíos en el mercado era favorable a los intereses rentistas de los señores del lugar; sin embargo, suponía una mayor competencia que podía incidir sobre los precios. Por este motivo, se tomaron medidas restrictivas en algunos lugares, que a veces se acompañaron con argumentaciones de tipo religioso, sobre todo en relación con ciertos productos alimenticios como la carne, el vino y el pescado. La serie de documentos sobre Belorado, reunida por el profesor Baer, puede ilustrar esta cuestión en un ámbito estrictamente rural. En esta villa tenía lugar un mercado franco todos los lunes. En 1301, Fernando IV libró un privilegio por el que se ordenaba que ningún judío de la judería de Belorado, ni de sus aldeas, pudiera entrar en la villa los lunes para comprar en su mercado. En 1325, Alfonso XI libró otro privilegio, esta vez en favor de la aljama de dicho lugar, ordenando que los judíos estén apartados de los cristianos, pero que se les permita tratar con ellos los lunes en el mercado. Posteriormente, este mismo monarca volvió a restablecer la prohibición existente respecto de la asistencia de los judios al mercado. La causa de estas tensiones residía en un grave quebranto de la convivencia vecinal, por la negativa de los judíos a colaborar en las obras de reparación de la torre del homenaje existente en la villa. El asunto ya había sido planteado en 1301, pero hasta principios del siglo XV no se llegó a un acuerdo. Existía un viejo contencioso entre el concejo y la aljama, motivado porque a los judíos se les exigía que barrieran las calles y reparasen la cerca en el sector contiguo a la judería. Como ellos se negaban, el concejo les impedía pacer en los prados co-

50 Nos referimos a esta cuestión en nuestro trabajo «Usura judía y préstamo eclesiástico. Contribución al estudio de los orígenes del censo al quitar en Castilla", en Encuentros en Sefarad. Ciudad Real 1987, págs. 71-102.

51 BAER, II, n. 235. 
munales y cortar leña en sus montes. Finalmente en 1408, los judíos de la villa recibieron una exención de impuestos a cambio de aceptar la obligación de reparar a su costa la muralla y torre mencionadas. Además, se llegó al acuerdo de que la aljama nombraría cada semana a dos personas encargadas de barrer las calles y plazas de la villa los jueves. A cambio se les permitía aprovecharse de los prados y montes comunales $^{52}$.

En otros aspectos de la vida cotidiana, la conciencia de la superioridad del cristianismo se trasladaba al plano puramente antropológico. Así se rechazaba la posibilidad de que el judío tuviera servidores cristianos, y mucho más si se trataba de un servicio doméstico. En reciprocidad, también se rechazó que los judíos pudieran prestar determinados servicios a los cristianos. Lo más frecuente es la prohibición de que los judíos fueran médicos, farmacéuticos, cirujanos o veterinarios, es decir profesiones relacionadas con la salud, en donde cualquier envenenamiento o crimen podía pasar desapercibido. Pero las ordenanzas de 1412 añaden también como profesiones prohibidas las de vendedores de pan y otros alimentos, herradores, zapateros, jubeteros, sastres, tundidores, calceteros, carniceros, pellejeros, traperos y recueros ${ }^{53}$. El ambiente en el que se producía este fenómeno estaba impregnado de rechazo religioso y temor a la contaminación producida por el contacto. El adulterio y las relaciones carnales entre cristianos y judíos se castigaban con la muerte ya en Las Partidas. Sin embargo, es posible que este hecho, cuya prohibición se repite hasta la saciedad en los textos, no tuviera un rechazo social tan claro en determinados ambientes de incredulidad religiosa ${ }^{54}$. También hay un rechazo a participar en algunas ceremonias religiosas que tienen lugar en coincidencia con los ciclos vitales, como la circuncisión, bodas o entierros ${ }^{55}$. Prohibición más tajante en el caso de los conversos, por ser considerada una prueba clara de criptojudaísmo ${ }^{56}$.

El deterioro de la convivencia había llegado a un punto en el que la sola presencia del judío podía ser considerada una provocación. Para

52 BAER, II, n. ${ }^{\circ}$ 112. Sobre la judería de Belorado, vid., FITA, F., «La aljama hebrea de BeIorado", BRAH, 29 (1896). Más recientemente, HuIDOBRo, L. y CANTERA, F., “Juderías Burgalesas (Beleña y Belorado)", Sefarad, Xill (1953), págs. 35-59.

53 BaER, II, n. ${ }^{\circ} 275$, puntos 2, 5 y 20.

54 El caso del judío comerciante de Medina de Pomar, estudiado por PÉrez Bustamante, R., es de interés a este respecto, vid. «Un proceso contra los judíos de Castilla la Vieja. Medina de Pomar 1430", en Encuentros en Sefarad, op. cit., págs. 45-70.

${ }_{55}$ Ordenanzas de Valladolid de 1412, título 4. BAER, II, n. 275.

s6 Vid. Ios trabajos de BEINART, H., Trujillo a jewish community in Extremadura on the eve of the expulsion from Spain. Jerusalem 1980, y Los conversos ante el tribunal de la Inquisición. Barcelona 1983. 
contrarrestarlo, había disposiciones desde el siglo XIII, contrarias al lujo y la ostentación en el vestir ${ }^{57}$. La humildad y la prudencia fue asumida plenamente por la minoría judía, incluso por su grupo dirigente. Las persecuciones de 1391 pusieron de manifiesto la gravedad de la situación y el peligro real que se corría. Las ordenanzas de 1432 dedican su quinto y último punto a tratar «sobre el negocio de los vestidos». En el mismo se prohíbe la utilización de vestidos lujosos, excepto en el caso de las "moãs por casar» y en determinadas fiestas señaladas, encomendando a cada cahl la elaboración de takkanot al respecto «...por quanto la diversidad es grande entre los qahles, en sus traies, e non se podria fazer tecana general (perfecta), que bastase a declarar todos los particulares que en ellos se debrian fazer ${ }^{58}$.

Nuestro trabajo es sólo una primera aproximación al estudio comparativo de las aljamas y concejos castellanos, en consecuencia, cualquier conclusión en este momento podría ser precipitada. No obstante, pensamos que puede resultar de utilidad insistir en la relacion existente éntre ambas instituciones, y abrir nuevas vías de investigación en relación con el antijudaísmo. Si observamos la evolución seguida por los concejos medievales, tendente hacia la consolidación de un poder oligárgico, cuya expresión más definida es el Regimiento ${ }^{59}$, parece evidente que la aparición de las aljamas en el siglo XIII responde a una tendencia similar en el seno de la población judía castellana. En este punto, la consideración de factores religiosos, así como otros puramente antropológicos, como las formas de vida cotidiana o de convivencia, es imprescindible para eludir simplificaciones excesivas.

La implantación de un régimen oligárquico en las aljamas encontró la oposición de grupos religiosos «pietistas» entre los judíos. Por otra parte, la minoría de poder judía se vio rechazada y perseguida por las oligarquías urbanas y por la nobleza, en un conflicto social cuya comprensión sólo es posible dentro del estudio de conjunto de la sociedad castellana de los siglos XIV y XV. En este sentido, pensamos que la crisis de las aljamas

\footnotetext{
7 Ayuntamiento de Jerez de 1268.

58 Fernández y González, op. cit, págs. 12-13.

59 En este punto, es importante tener en cuenta las conclusiones aportadas por el volumen Concejos y ciudades en la Edad Media Hispánica. Madrid 1990, donde, por cierto, no hay ningún trabajo dedicado a las aljamas.
} 
es también un síntoma de la crisis de la minoría dirigente de la población judía; si bien, este declive estuvo acompañado por un reforzamiento de la conciencia religiosa del grupo, como puede observarse en los años anteriores a la expulsión, y después de ésta, en las comunidades surgidas en el Norte de África ${ }^{60}$.

60 Además de los trabajos de BEINART, citados en nota 56, dedicados principalmente a los conversos judaizantes en la época de la expulsión, puede verse el de LAREDO, A. I., sobre las comunidades judías de origen español en Marruecos. "Las Taqanot de los expulsados de Castilla en Marruecos y su régimen matrimonial y sucesoral», en Sefarad, VIII (1948), págs. 245276 . 